\title{
Open Stacks in Library Design
}

\section{Lorrie McAllister and Shari Laster}

Technological innovation has fostered structural shifts in scholarly communications and cooperation among academic institutions over time. The shift into ubiquitor soligital content ushered in transformational changes to research and teaching. The change presents an opportunity for libraries to transform themselves as well, rethinki in how we select, display, share, and curate creative, scholarly, and informational works in all formats.

People who use academic libraries have great interest in where these works reside, how they are accessed, and how their future is ensured. Wegt Arizona State University (ASU) Library propose that the bookless library model represents an unfulfilled promise to those we serve. Instead, we posit that academic librollies can still host tangible materials in multiple formats while adapting a user-fogged and intentional design approach to scholarly works, keeping them in openly accessible shelves in our buildings, even as we increase available study space. Open stasks, available for viewing and browsing by the public, offer an intentionally desigede, material experience as a key component of space design. They also remind us thet not all knowledge exists in digital form.

\section{Case for Open Stacks}

In our current sea of digital information, the metadata describing information of academic interest and utility are roòt sufficient to resolve every search query and research process. The more purely tiansactional the query, the easier it is for commercial search engines to satisfy. On the ouner hand, the more a question is open to interpretation, the harder it is to provide asatisfactory experience for the searcher. Library staff routinely respond to compley queries and challenging questions by means of a reference interview, in which they darify the user's information needs, which might differ from the question posed, and cirect the user to appropriate resources. Online search and discovery mechanisms have yet to develop sophisticated interactions with users about their needs. Therefore, the expertise and human insight of library staff are still valuable and necessary to scholars and learners for higher-order search and discovery processes. 
The online catalog, commercial discovery layers, the open Web, and books available for browsing in libraries all aid in the process of discovery of resources. An absence of books means one fewer discovery method available. It is important, therefore, that librar-

An absence of books means one fewer discovery method available. It is important, therefore, that libraries retain physical books in open stacks to offer our communities a handson opportunity to discover and use resources. ies retain physical books in open stacks to offer our communities a hands-on opportunity to discover and use resources. Applying the same expertise and human insight to decisions about the collections we make immediately available on site also affords an opportunity to increage the effectiveness of in-person discovery.

We intentionally use the term open stacks as a counterpoin: to open educational resources, ninch are publicly accessible resourdes for teaching,

learning, and exploration. When academic libraries open their doors, whether to K-12 learners, independent researchers, community archival and púnc history projects, or those seeking access to government information, we believo that print collections and other tangible resources are public goods that should bo discoverable and usable by the public. We propose open stacks as a manifestatior foft the public social institution of library collections, following the norms of other sofgitinstitutions, such as open government or open science. With open stacks, open coloracterizes the participatory nature of the collection development process, the distriguted benefit of access to all who enter our building, and the freedom to consume, thodify, and share the conceptual components and outputs of the collection developerent process. ${ }^{1}$ We consider our buildings and spaces to be educational opportunities, opening them to people to use information and build knowledge from the resoulrces readily available at hand.

\section{Think Globally, Act Locally}

Print resources, priplarily books and journals, are ubiquitous in most academic libraries and still vitâl $t 5$ many disciplines. There is little conversation in national library forums, howerer, about developing general print collections, except perhaps how to reduce ther size. Most print collection development activities are limited to the needs of local eonstituents, for example, the students, faculty, and staff of the institution and possibiy nearby institutions serving overlapping patron groups. As such, planning and decisions are limited to a local context. Where active planning and decision-making have waned, the shelves fill with books ordered title-by-title, selected based on faculty requests, acquired at the discretion of a library bibliographer, or selected from a vendor approval plan. Over time, the shelves simply fill up, and infrequently used materials are eventually weeded or moved off site.

The local context is of utmost importance when engaging users of our physical library spaces. However, understanding how our local print collections connect to collections at other libraries and to materials in other formats-and how all these collections overlap, complement one another, and, together, constitute a massive body of 
scholarly resources-is relevant to our mission from both economic and social perspectives. Collaboration is key to new knowledge production and, therefore, to the global welfare. We propose that academic libraries in the United States, as privileged institutions, should consider the substance of our extended national and global library networks when acting to meet local needs.

We see the need for a concerted effort to design local collections that are joined in a networked national print collection. There is momentum for shared print archiving at a regional and now a national scale for journals with the Rosemont Shared Print Alliance, in which academic and research libraries partner

... academic libraries in the United States, as privileged institutions, should consider the substance of our extended national and global libraro networks when acting to meet local needs. to store print periodicals; ${ }^{2}$ for monographs with the HathiTrust Shared Print Program, in which member libraries agree to keep millions of volumes corresponding to the print titles in the HathiTrust Digital Library; ${ }^{3}$ and for federal government documents with the United States Government Publishing Office's "National Plan for Access to U.S. Government Information?" which extends the preservation mandate of the Federal Depository Library Program. "Print will not "disappear" in our lifetimes, but some resources for scholarship agd learning will become more difficult to find, access, and use, especially when academic libraries deaccession print collections in ad hoc or uncoordinated efforts.

Rethinking the role of academic libtary print collections as a public good is a shared responsibility. More work is needed to the corstand the collective national and global print collection and its value, and to cerfider how we might curate our local print collections differently if we knew their impact at a larger scale.

\section{Intentional Design}

ASU Library has prtively pursued the charge from ASU President Michael Crow to reinvent and trahsform its space, collections, and services as part of the New American University radel. This model seeks to redefine the American public research university as a "cornprehensive knowledge enterprise dedicated to the simultaneous pursuit of excellence, broad access to quality education, and meaningful societal impact." 5 Tenets of our approach to President Crow's challenge are designing for inclusion, for wide access, and for flexibility to account for rapid changes in twenty-first century higher education. ASU Library sought out other libraries with a sustained or renewed interest in print collections, undertaking a one-year collaborative planning process to explore and define the future of print in academic libraries. This process resulted in a 2017 white paper, "The Future of the Academic Library Print Collection: A Space for Engagement." It explores potential approaches and actions for academic libraries to foster engagement with their collections and their communities, and includes materials and tools to help guide individual libraries toward a people-centered and data-driven approach to print curation tailored to their local contexts. 
Based on this effort, ASU Library began work in January 2018 on a three-year implementation grant from the Andrew W. Mellon Foundation to reinvent the library's strategy and practices for open stack collections. This project enables ASU Library to conceptualize and develop intentionally designed print collections to engage, educate, and inspire scholars and learners. Insights resulting from this project will inform the curation of the open stacks in the renovated Hayden Library, scheduled to open in early 2020. Hayden Library serves over 50,000 students enrolled in residential programs at Arizona State University's Tempe campus. ${ }^{7}$ The renovation of the 252,670-square-foot library provides an opportunity to explore and better understand why and how people use this large, primarily undergraduate, library.

The numbers of degree and nondegree programs at ASU increase every year as the university aims to become a "fifth wave" institution, which expands the capa (1) and reach of higher education to millions more Americans and people around the world otherwise at risk of being left out of a global knowledge economy. ${ }^{8}$ The design principles for renovating this central building on the Tempe campus reflect the reed for flexible spaces supporting a wide variety of academic and intellectual engagements, along with quiet study and reflection. The plan for the building increases lassroom and study spaces. It also opens additional entrances and cross-through pints to further integrate Hayden Library into Tempe campus life, especially during the summer months, when members of the ASU community naturally seek air-cerditioned settings. The plan also significantly decreases the open stack footprint in foe building, necessitating a careful look at the print collections that will return to Ojayden Library. We want to learn how our print collections contribute to how usersperceive and distinguish different parts of the facility, and how those perceptions iritersect with the services we provide.

\section{A Key Component of Space Design}

A driving force for the open gacks concept is the continually increasing importance of space in academic libraries, which asks that we assess our spaces as services to our us-

... the print collections that

are retained siould be a key componesit of space design, servingas important actors within the space and engaging their audience rather than serving merely as a backdrop for study. ers. Pressures to increase areas for student study and group work, faculty research, and coffee breaks and refreshments most often leave their traces on new library designs by reducing the overall space devoted to collections. We believe that the print collections that are retained should be a key component of space design, serving as important actors within the space and engaging their audience rather than serving merely as a backdrop for study.

By designing a physical space, we also design the experience of that space. By deliberately including print collections as part of the experience, we create the opportunity for programmed events and displays that explore books and other tangible formats as a vital force in the library, in the academy, and in broader contexts. Much of the information embedded in print resources cannot be shared widely on the Internet due to 
copyright law, cultural and privacy concerns, commercial interests, or lack of funding to digitize and make the content available. In addition, readers may prefer print for some purposes even when a digital surrogate is available. While the subjective experience of reading or browsing a book in print is not inherently better or worse than engaging with the same content in a digital format, the experience is nevertheless different. Depending on the book, and the reader, that difference can be meaningful.

As people move through and interact with library spaces, how they perceive library resources can encourage new knowledge and ways of thinking. Aspirational missions of the academic library to enable and support individual academic success, to foster exploration and discovery, and to curate and steward narratives and records of collective social change are still relevant and important. The digital age has moved more of the experience we create and facilitate to a virtual setting, but the in-person experi-

Library spaces can become destinations for inspiration, discussion, leaghing, and scholarship, and we propest that print collections are essentialin this endeavor.

ence still matters. As a result, the interpretation and presentetion of our print collections still matter. Library spaces can become destinations for inspiration, discussion, learning, and scholarship, and we propose that print collectiors are essential in this endeavor.

\section{Experimertation}

The open stacks at ASU Library will begome more specialized and more highly curated. The library will employ a user-centered, inclusive, and data-driven approach to collection development, display, and ongoing analysis. To achieve this, we have undertaken a series of experiments to better understand selection methodologies that will engage the various constituents who win experience our collections in Hayden Library and other library locations. One preliminary experiment now underway, "Required Reading," is a student curation proiect in which students express their interests, share meaningful works with others and help build the library's collections. ${ }^{9}$ The project included an open call for judergraduates to submit their top "required reads," a description of the importarce of each of these books in their lives, and a photograph of themselves. The library purchased student-endorsed books not already in our collections and then collocated collections from two of the submissions in a high-traffic library location on the Tempe campus. We hope that the display will grab the attention of passersby while providing a platform for the voices of students regarding the meaning and importance of library collections. We plan to review circulation and other use data after a suitable interval of time.

As of this writing, ASU Library is developing "10 Compelling Ideas" as discrete open stack collection development experiments. We selected these projects through a card sorting process, matching an internal stakeholder with an external stakeholder, a physical library location where the experiment will take place, and an assessment mechanism. The resulting set of experiments will inform decision-making about the hundreds of thousands of volumes that we will bring back to the renovated Hayden Library in 
2020. We will track engagement with community-based initiatives as we seek partners to suggest parameters for collections, identify titles worthy of inclusion, and apply their experiences to build collections. We can also gain information from those who engage with our collections by encouraging patrons to share reactions and reflections.

One experiment we plan to explore is a collection about collecting. We will seek input and insight from other collectors at ASU, whether they work with maps, insects, art, meteorites, or other collectibles. Then we will develop a bookstore-style display about why, how, and what people collect. This project offers an opportunity to reflect on why libraries collect and the impact that collections have on individuals, communities, and society. We believe that this effort will reveal some of the hazards as well as the benefifs of people superimposing order upon the world. In addition, this experiment aims to

The more our communities know about libraries, library processes, and information resources, the more they will make use of what we offer increase transparency in collecting $\mathrm{p}$ ○cesses to help patrons learn about scholady and information resources. This collection, and other deliberately designed open stacks collections, can also be explored as data, allowing us to share, examine, and smprove the principles informing the desion. 10 The more our communities know about libraries, library processes, and information resources, the more they will make use of what we offer and, we believe, the bethery prepared they will be as learners and members of society. This relationship works both ways: the more we learn about our communities and how they interact with books and library collections, the better we will create collections for the future.

\section{The Eiture of Open Stacks}

By mobilizing the conversation about print collection development at a national scale, we can move toward a shared understanding of goals for a national and global print collection that will beneti: generations of scholars. These conversations may then inform shared print archiving initiatives as well as local open stack collection development. We also hope that academic libraries will use open stack collections as part of space planning and service eforts. The American Library Association (ALA) and other professional association's lack a formal venue for conversations about general print collection developmen Nevertheless, we see an opportunity to expand existing conversations around shared print collections to include the deliberate design of open stacks in library spaces. In the months to come, we hope to revive these conversations at professional meetings and among those who share our interests. ${ }^{11}$

Lorrie McAllister is the associate university librarian for collections services and analysis at the Arizona State University Library in Tempe; she may be reached by e-mail at: lorrie.mcAllister@ asu.edu.

Shari Laster is the head of open stack collections at the Arizona State University Library in Tempe; she may be reached by e-mail at: shari.laster@asu.edu. 


\section{Notes}

1. Here we rely on the social praxis model developed by Matthew Smith and Ruhiya Seward. See Matthew Longshore Smith and Ruhiya Seward, "Openness as Social Praxis," First Monday 22, 4 (2017), http:/ / firstmonday.org/ojs/index.php/fm/article/view / 7073.

2. Rosemont Shared Print Alliance, "Welcome to the Rosemont Shared Print Alliance," 2018, https: / / www.rosemontsharedprintalliance.org.

3. HathiTrust Digital Library, "Shared Print Program," https: / / www.hathitrust.org/shared_ print_program.

4. United States Government Publishing Office, Federal Depository Library Program, "The National Plan for Access to U.S. Government Information," 2016, https: / www.fdlp.gov / project-list/national-plan.

5. Arizona State University (ASU), “The New American University Is ASU's Reconceptualization of 21st Century Higher Education," https: / / newamericanuriversity. asu.edu.

6. ASU Library, "The Future of the Academic Library Print Collection: A Spacefor Engagement," 2017, https: / / lib.asu.edu/sites / default / files / marketing / SU\% 20 Whitepaper\%20-\%20Which\%20Books.pdf. See also ASU Library, "The Euture of Print," https: / / lib.asu.edu/futureprint.

7. ASU, "ASU Facts," https:/ / facts.asu.edu/.

8. ASU, Office of the President, “Our Imperative Is Innovation,' 3016, https:/ / president.asu. $\mathrm{edu} /$ node $/ 2110$.

9. This project was led by ASU Library's open stacks curafer, Rachel Leket-Mor. To learn more, see ASU Library, "Students Curate Collections Chat Inspire, Reveal," 2018, https: / / lib.asu.edu / librarychannel/Students-curate-collegtions-inspire-reveal.

10. Here, we intend to learn from the burgeoning collections as data communities of practice. For more, see "Always Already Computational-Collections as Data," 2018, https:/ / collectionsasdata.github.io/.

11. Contact the authors for information about opportunities for conversation. 


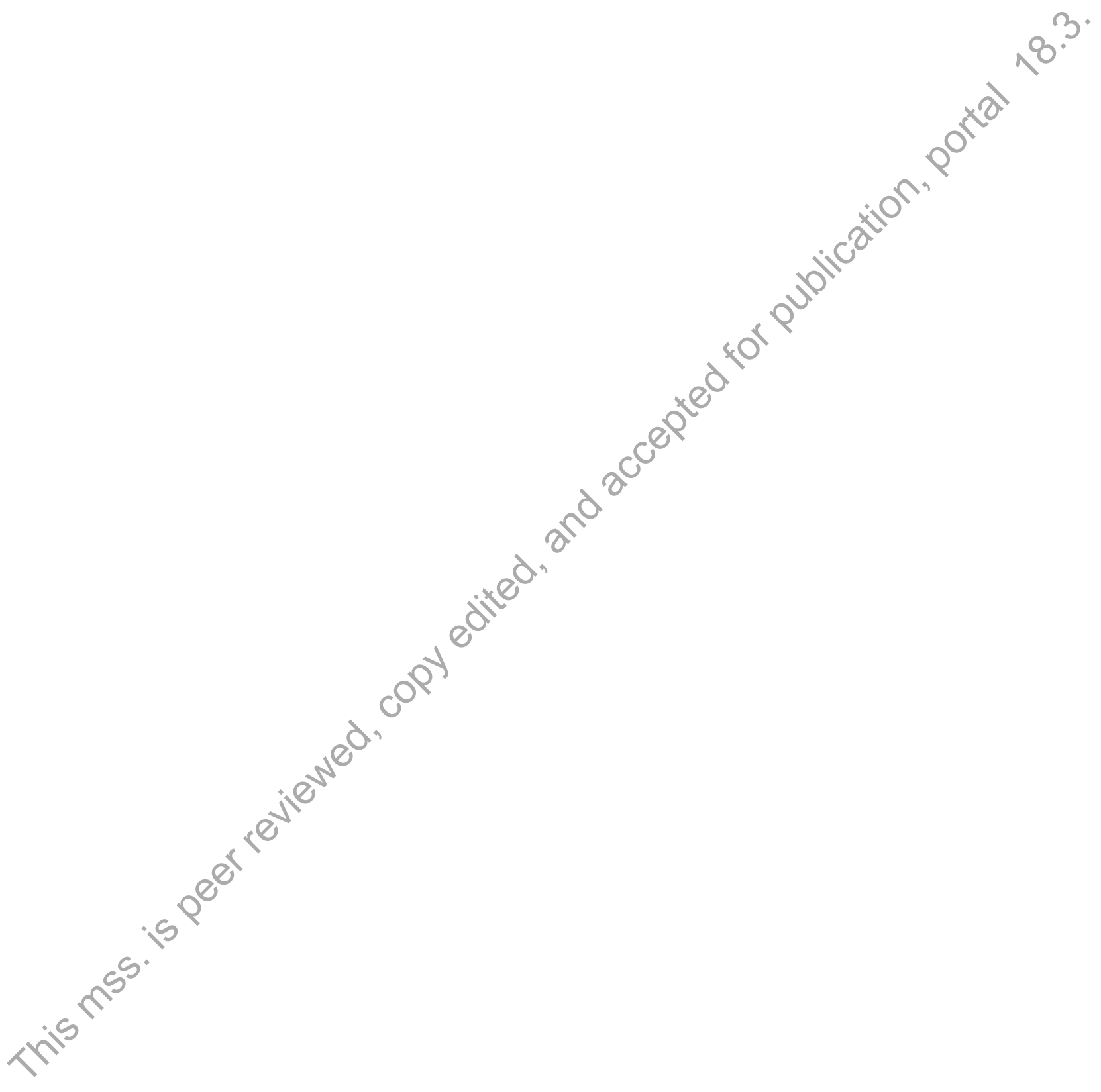

